\title{
Expression of Cav-1 in tumour cells, rather than in stromal tissue, may promote cervical squamous cell carcinoma proliferation, and correlates with high-risk HPV infection
}

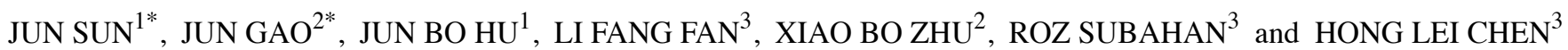 \\ ${ }^{1}$ Department of Pathology, Maternal and Child Health Hospital of Hubei Province,Wuhan 430072; \\ ${ }^{2}$ Department of Molecular Pathology, Wuhan Nano Tumor Diagnosis Engineering Research Center, Wuhan 430072; \\ ${ }^{3}$ Department of Pathology, School of Basic Medical Science, Wuhan University, Wuhan 430071, P.R. China
}

Received November 28, 2011; Accepted January 16, 2012

DOI: $10.3892 /$ or.2012.1703

\begin{abstract}
Altered expression of caveolin-1 (Cav-1) is observed in various types of cancers. However, little research has been reported regarding the correlation between the expression of Cav-1 and cervical cancer. Here, we investigated the clinical significance of Cav-1 expression using quantum dot (QD)-based immunofluorescence staining in cervical cancer and its correlation with high-risk human papilloma virus (HPV) infection detected by chromogenic in situ hybridization. Our results showed that the positive rates of Cav-1 protein in normal cervical mucosa, CIN, cervical adenocarcinoma and SCC were: 0, 33, 19 and 55\%, respectively. The differences in Cav-1 protein expression in cervical SCC compared to the other three groups were all statistically significant. Absence of stromal Cav-1 protein in 58 cases of cervical SCC was $67 \%$. The positive rates of the Cav- 1 protein in tumour and stromal cells of cervical SCC were not correlated with clinicopathological parameters. In the cervical SCC tissues, Cav-1 expression in tumour cells was not associated with stromal Cav-1 expression, but a positive correlation existed with the PCNA protein and high-risk of HPV infection. The results presented here suggest that expression of Cav-1 in the tumour cells, rather than in the stromal tissue surrounding the tumour,
\end{abstract}

Correspondence to: Dr Hong Lei Chen, School of Basic Medical Science,Wuhan University, Wuhan 430071, P.R. China

E-mail: hl-chen@whu.edu.cn

*Contributed equally

Abbreviations: HR-HPV, high-risk human papillomavirus; Cav-1, caveolin-1; CIN, cervical intraepithelial neoplasia; SCC, squamous cell carcinoma; AC, adenocarcinoma; TMA, tissue microarray; PCNA, proliferating cell nuclear antigen; QD-IHC, quantum dots immunofluorescent histochemistry; ISH, in situ hybridization; HNSCC, head and neck squamous cell carcinoma

Key words: cervical cancer, caveolin-1, human papilloma virus, quantum dots, immunofluorescence may promote cervical SCC cell proliferation, and correlates with high-risk HPV infection.

\section{Introduction}

Cervical cancer is one of the most common cancer among women worldwide, and its incidence is higher in people of low socioeconomic status in developing countries, including China. It is well known that cervical carcinogenesis is caused by persistent oncogenic high-risk human papillomavirus (HR-HPV) infection $(1,2)$. However, not all of the infected women will develop cervical cancer, still other genetic and epigenetic factors including tumour suppressor gene, oncogene, cell cycle regulating factors and apoptosis, may be involved in tumour progression (1).

The caveolin (Cav) family includes Cav-1, Cav-2 and Cav-3. Cav-1 is the major structural protein of caveolae and functionally regulates the activity of many signaling molecules, which are potentially involved in the development of human cancer. Cav-1 is widely expressed in fully differentiated or quiescent cells, such as adipocytes, fibroblasts, alveolar epithelial cells, endothelial cells and smooth muscle cells. Previous studies of Cav-1 in various types of cancer showed two contrary results. On one hand, expression of Cav-1 is increased in cancer of the prostate (3), pancreas (4), breast (5), colon (6), tongue (7) and esophagus (8), thus, indicating that it plays a positive role in tumour progression. On the other hand, expression of Cav-1 is decreased in the lung (9), colon (10), ovary (11), breast $(12,13)$, stomach (14) and thyroid cancer (15). Cav-1 has a different expression pattern across tissues in different organs, despite such tissues having the same histological type, such as squamous cell carcinomas. These data imply that Cav-1 may have multiple activities in cancer depending on its interaction with other signaling molecules and the specific cell type or tissue in which it is expressed. Therefore, whether caveolins promote or suppress tumour progression remains controversial.

Cervical tumours are composed of malignant epithelial cells and tumour stroma. Recently, more and more evidence has identified that stromal components in the tumour microenvironment, including the extracellular matrix and cell types such as fibroblasts, vascular endothelial cells, immune and 
inflammatory cells, have a profound influence on the development and metastasis of tumours. There is evidence that the presence of Cav-1 in the tumour microenvironment can regulate tumour development. Witkiewicz, et al (16) reported that an absence of stromal Cav-1 expression in human breast cancers is a powerful single independent predictor of early disease recurrence, metastasis, tamoxifen-resistance and poor clinical outcome.

To understand the role of Cav-1 including tumour and stromal expression and HR-HPV infection in the progression of cervical lesions, a series of consecutive biopsies and resected specimens with progressing lesions from cervical intraepithelial neoplasia (CIN) to invasive cervical cancer were investigated. In the present study, we thus analysed the Cav-1 expression status in 89 patients with cervical cancer and 10 cases of normal cervical tissues and 30 cases of CIN were used as control, then clarified their correlation with clinicopathological parameters and HR-HPV infection.

\section{Materials and methods}

Patients and cervical specimens. A total of 89 samples including 73 cases of cervical squamous cell carcinoma (SCC) and 16 cases of cervical adenocarcinoma (AC) who underwent total hysterectomy due to complaints other than uterine cervical lesions such as uterine fibroids, and endometriosis, were studied. Thirty biopsy samples had CIN diagnosis (10 cases with CIN1, 8 cases with CIN2, and 12 cases with CIN3), and 10 biopsy samples had normal cervical mucosa. All these cases were treated in Department of Pathology, Maternal and Child Health Hospital of Hubei Province, between 2006 and 2009. The diagnosis of all the cases was reviewed and reconfirmed by two experienced pathologists (J.B.H. and J.S.). Primary cervical squamous cell carcinoma patient characteristics including World Health Organization TNM stage, pathological grade are shown in Table I. Approval for this study was obtained from the ethics committee of Maternal and Child Health Hospital of Hubei Province.

Tissue microarray construction. All 73 cases of cervical SCC were randomly selected for tissue microarray (TMA). Haematoxylin and eosin stained sections of the selected tumours were examined and representative areas of solid tumour identified for sampling. A tissue core of diameter $1.5 \mathrm{~mm}$ was punched from each donor block and transferred to a recipient block of maximum 96 cores using a tissue-arraying instrument (Beecher Instruments, Silver Spring, MD, USA). Sections $(4 \mu \mathrm{m})$ were consecutively incised from the recipient block and transferred to poly-lysine-coated glass slides. Haematoxylin and eosin staining was performed on TMA for the confirmation of tumour samples.

Quantum dot-based immunofluorescence histochemistry. Cav-1 immunoreactivity was detected in all 129 cervical specimens using a primary rabbit antihuman polyclonal antibody (diluted 1:300; Santa Cruz Biotechnology, Santa Cruz, CA, USA) and performed by quantum dot immunofluorescent histochemistry (QD-IHC) according to the manufacturer's instructions (Wuhan Jiayuan Quantum Dots Co., Ltd., Wuhan, China). The detailed procedure was performed as previously
Table I. Correlation between expression of Cav-1 protein in the tumour cells and clinicopathological parameters of cervical squmous cell carcinomas.

\begin{tabular}{|c|c|c|c|c|c|}
\hline \multirow[b]{2}{*}{ Group } & \multirow[b]{2}{*}{ Cases } & \multicolumn{2}{|c|}{ Cav-1 } & \multirow[b]{2}{*}{$\chi^{2}$ value } & \multirow[b]{2}{*}{$\mathrm{P}$-value } \\
\hline & & $-(\%)$ & $+(\%)$ & & \\
\hline Age & & & & 1.028 & 0.311 \\
\hline$\geq 47$ & 29 & $11(38)$ & $18(62)$ & & \\
\hline$<47$ & 44 & $22(50)$ & $22(50)$ & & \\
\hline Grade & & & & 0.416 & 0.519 \\
\hline $\mathrm{I}+\mathrm{II}$ & 25 & $10(40)$ & $15(60)$ & & \\
\hline III & 48 & $23(48)$ & $25(52)$ & & \\
\hline \multicolumn{6}{|l|}{ Tumor stage } \\
\hline $\mathrm{T} 1$ & 62 & $30(48)$ & $32(52)$ & 1.681 & 0.325 \\
\hline $\mathrm{T} 2+\mathrm{T} 3$ & 11 & $3(27)$ & $8(73)$ & & \\
\hline TNM stage & & & & 3.319 & 0.068 \\
\hline $\mathrm{I}+\mathrm{II}$ & 52 & $20(38)$ & $32(62)$ & & \\
\hline III+IV & 21 & $13(62)$ & $8(38)$ & & \\
\hline $\begin{array}{l}\text { Lymph node } \\
\text { status }\end{array}$ & & & & 2.434 & 0.119 \\
\hline $\mathrm{N}_{0}$ & 53 & $21(40)$ & $32(60)$ & & \\
\hline $\mathrm{N}_{1-3}$ & 20 & $12(60)$ & $8(40)$ & & \\
\hline $\begin{array}{l}\text { HPV 16/18 } \\
\text { infection }\end{array}$ & & & & 5.764 & 0.016 \\
\hline Negative & 17 & $12(71)$ & $5(29)$ & & \\
\hline Positive & 56 & $21(37)$ & $35(63)$ & & \\
\hline PCNA status & & & & 16.579 & 0.000 \\
\hline Negative & 14 & $13(93)$ & $1(7)$ & & \\
\hline Positive & 59 & $20(34)$ & $39(66)$ & & \\
\hline Stromal Cav-1 & & & & 3.155 & 0.076 \\
\hline Negative & 39 & $17(44)$ & $22(56)$ & & \\
\hline Positive & 19 & $13(68)$ & $6(32)$ & & \\
\hline
\end{tabular}

described (17). The positive signal was observed and the obtained images captured via Olympus BX51 fluorescence microscopy (CCD DP72). The immunofluorescence signals were bright red (605 $\mathrm{nm}$ QDs), and photostable. Positive staining of Cav-1 was located in the cell membrane and cytoplasm. In addition, negative control serum was applied to a section of cervical SCC as a negative control. Normal blood vessel endothelial cells naturally abundant in Cav-1 were used as positive internal controls (Fig. 1A).

Scoring of the immunofluorescent results. At least 100 cells were randomly selected and counted from five representative fields of each core using a x20 objective in a blinded manner by two independent observers (J.B.H. and J.S). Positive rates of Cav-1 in tumour cells detected by QD-IHC staining were assessed according to protocol outlined by Ando et al (18). In cervical AC tissues were classified into two groups: negative $(-)$ and positive $(+)$ by the threshold between $0 \%$ and the others because Cav-1-positive cells were $<5 \%$ in most tumours. In cervical SCC specimens, expression of Cav-1 was scored 

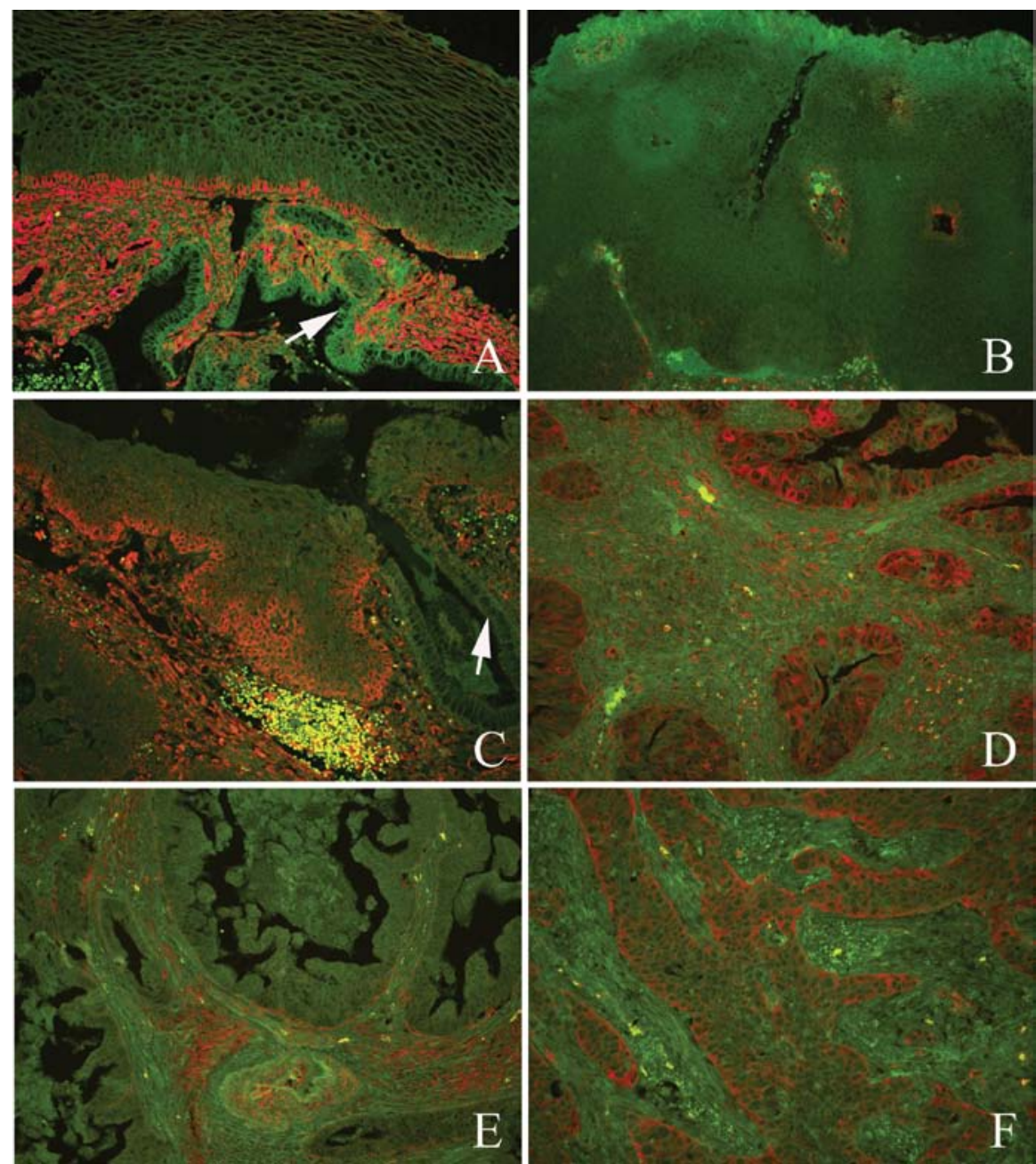

Figure 1. Expression of Cav-1 protein detected by quantum dot immunofluorescent method in the human different cervical lesions. (A) Positive expression of Cav-1 protein in the basal cells of normal cervical epithelium and stroma, negative expression of Cav-1 in the other parts including glandular epithelium (white arrowhead). (B) negative expression of Cav-1 in the CIN tissues. (C) Positive expression of Cav-1 in the CIN tissues, but negative in the glandular epithelium (white arrowhead). (D) Positive expression of Cav-1 in the stromal and tumour cells of cervical adenocarcinoma. (E) Negative expression of Cav-1 in the tumour cells of cervical adenocarcinoma, but positive in the stroma. (F) Positive expression of Cav-1 in the cancer cells of cervical SCC, but negative in the stroma (original magnification, x200).

as follows according to the proportion of positive staining throughout the entire core: 0 , negative or $<10 \% ; 1,<33 \% ; 2$, $33-67 \%$; and $3,>67 \%$. The status of Cav-1 immunofluorescent staining was classified as negative for scores of 0 or 1 and positive for scores of 2 or 3 . Negative or absent expression of stromal Cav-1 was no staining, otherwise, regarded as positive expression.

Quantumdot double immunofluorescent labeling.Co-expression of Cav-1 and proliferating cell nuclear antigen (PCNA) proteins were detected in cervical SCC TMA by quantum dot double immunofluorescent labeling staining according to the manufacturer's instructions (Wuhan Jiayuan Quantum Dots Co., Ltd.). All dilution steps (antibodies and QDs) were performed in TBS containing $2 \%$ bovine serium albumin (BSA, Sigma, St. Louis, MO, USA). Antigen retrieval was performed in citric acid $(10 \mathrm{mM}, \mathrm{pH} 6.0)$ at $95^{\circ} \mathrm{C}$ for $10 \mathrm{~min}$, followed by cooling for $30 \mathrm{~min}$. For antibody bindings, sections were first incubated in $2 \% \mathrm{BSA}$ buffer at $37^{\circ} \mathrm{C}$ for $30 \mathrm{~min}$, and then at $4^{\circ} \mathrm{C}$ overnight in Cav-1 and mouse anti-PCNA monoclonal antibody $(1: 150$ dilution, Santa Cruz Biotechnology). Negative control samples were prepared in parallel but the primary antibody was replaced with TBS. Sections were then washed three times with TBS-T (0.5\% Tween, $0.1 \mathrm{M}$ Tris-base, $0.9 \% \mathrm{NaCl}$ and $\mathrm{pH}$ 7.6) for $5 \mathrm{~min}$ each time, and incubated in biotinylated goat anti-mouse IgG (1:400 dilution, Jackson ImmunoResearch, West Grove, PA) at $37^{\circ} \mathrm{C}$ for $30 \mathrm{~min}$. For QD conjugation, antibody-binding sections were incubated in $2 \% \mathrm{BSA}$ buffer again at $37^{\circ} \mathrm{C}$ for $10 \mathrm{~min}$, incubated in QDs $(605 \mathrm{~nm})$ conjugated to streptavidin (1:200, Wuhan Jiayuan Quantum Dots Co., Ltd.) and QDs $(545 \mathrm{~nm})$ conjugated to goat anti-rabbit IgG $(1: 100$, Wuhan Jiayuan Quantum Dots Co., Ltd.) for 45 min, rinsed three times with TBS-T for 5 min each, and finally sealed with $90 \%$ glycerine (Sigma). The immunofluorescent signal was observed by Olympus BX51 fluorescence microscopy (CCD DP72). PCNA positive signals were bright red, and Cav-1 were green. Negative control only had autofluorescence signal.

$H P V$ detection by in situ hybridization. Sections of cervical SCC TMA (4 $\mu \mathrm{m})$ was deparaffinized and hydrated sections 

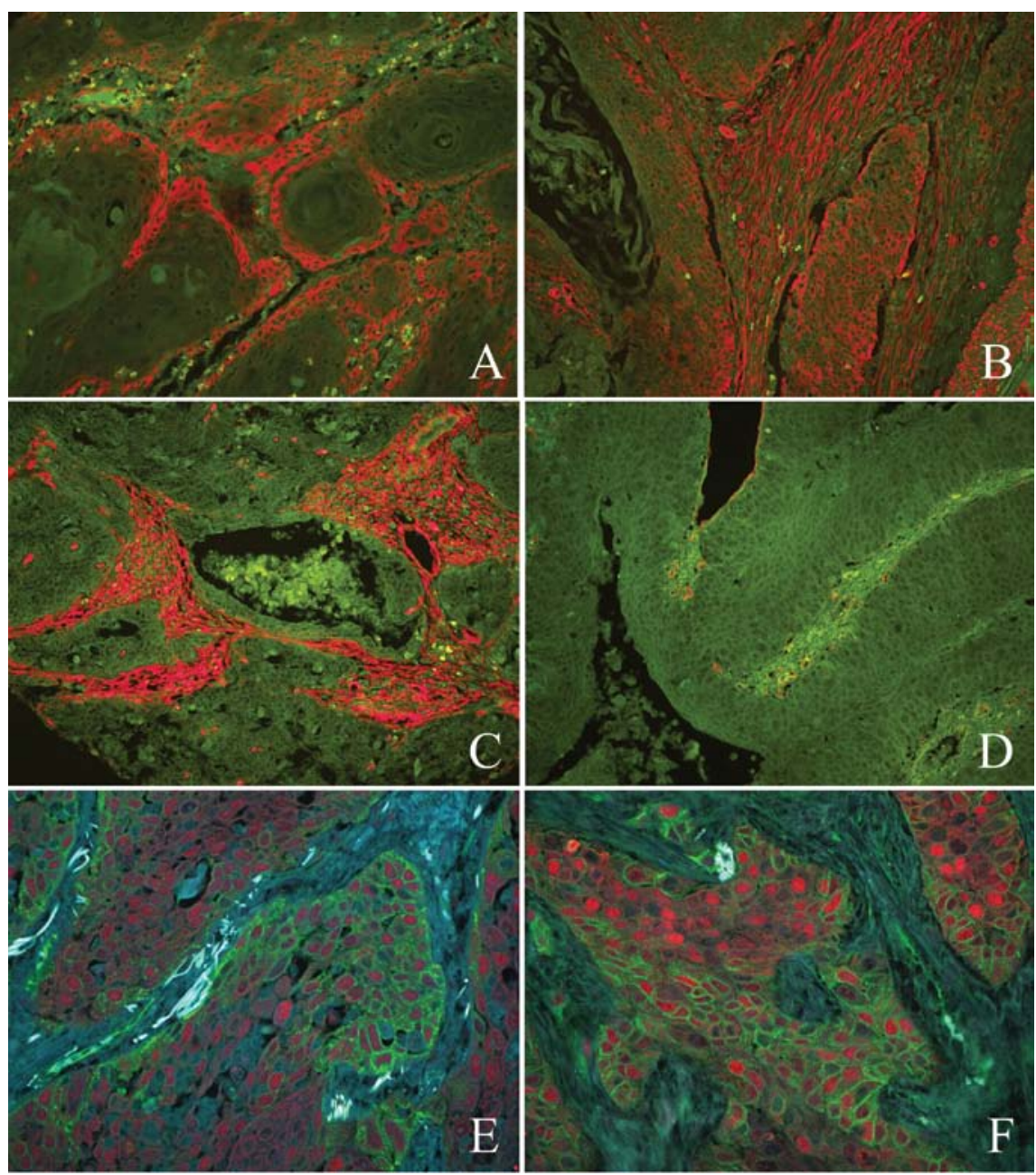

Figure 2. Expression of Cav-1 protein and co-expression of Cav-1 and PCNA proteins detected by quantum dots immunofluorescent method in the cervical squamous cell carcinoma. (A) Positive expression of Cav-1 protein in the tumour cells of cervical SCC, stronger signal in the tumour cells of peripheral cancer nest. (B) Positive expression of Cav-1 in the stromal and tumour cells of cervical SCC. (C) Negative expression of Cav-1 in the tumour cells of cervical SCC, but positive in the stroma. (D) Negative expression of Cav-1 in the stromal and tumour cells of cervical SCC. (E and F) Positive signal of PCNA protein located in the nuclus, bright red. Positive signal of Cav-1 protein showed green, located in the cell membrane and cytoplasm. Co-expression of Cav-1 and PCNA proteins was detected in the most of tumour cells (ultraviolet light excitation), (original magnification, A-D x200; E-F x400).

were stained using biotin-labelled HPV 16/18 DNA probes (PanPath, Amsterdam, The Netherlands) and the BIO-HRP Rembrandt ${ }^{\circledR}$ Universal DISH detection kit (PanPath). Detection and staining was carried out according to the manufacturer's instructions. Assessment of in situ hybridization (ISH) signals was carried out with Olympus BX51 microscopy (CCD DP72). A tissue block from a confirmed HPV-positive cervical carcinoma was used as positive control. Dark brown to black punctate or diffuse nuclear staining was regarded as being positive for HPV 16/18.

Statistical analysis. All statistical analyses were performed by the SPSS 18.0 software package for Windows. The $\chi^{2}$ test and Fisher's exact test (2-sided) were used to analyze the correlations between Cav-1 expression in the tumour and stromal cells and the patients' clinicopathological parameters. Correlations between Cav-1 expression in the tumour cells and PCNA, HR-HPV infection, stromal Cav-1 were analysed via Spearman rank correlation. P-values $<0.05$ were considered significant.

\section{Results}

Expression of Cav-1 protein. Expression of Cav-1 immunoreactivity was observed at the cell membrane and cytoplasm. Focal dot-like immunoreactivity for Cav-1 was detected in normal cervical squamous epithelium cells (Fig. 1A) and most of CIN (Fig. 1B), but strong positive staining in the capillary endothelial cells, fibroblasts and smooth muscle cells (Figs. 1A-D and 2B and C). It is interesting that completely negative expression of $\mathrm{Cav}-1$ protein was found in the cervical glandular epithelium (Fig. 1A and C). Diffuse positive staining of Cav-1 in the part of CIN, cervical adenocarcinoma, SCC was detected (Figs. 1C-F and 2B), but tumour cells in some cases including cervical adenocarcinoma and SCC demonstrated negative for Cav-1 (Figs. 1E and 2C and D).

Stronger positive staining of Cav-1 was observed in tumour cells of the peripheral cancer nests of some SCCs (Fig. 2A). The positive rates of Cav-1 in the normal cervical squamous epithelium, CIN, cervical adenocarcinoma, SCC was $0(0 / 10), 33 \%(9 / 30), 19 \%(3 / 16)$ and $55 \%(40 / 73)$, 
Table II. Cav-1 protein expression in the different cervical lesions.

\begin{tabular}{lccccc}
\hline & & \multicolumn{3}{c}{ Cav-1 } & \\
\cline { 3 - 4 } Different groups & Cases (n) & $-(\%)$ & $+(\%)$ & $\chi^{2}$ & P-value \\
\hline Normal epithelium $^{\mathrm{a}}$ & 10 & $10(100)$ & $0(0)$ & $3.871^{\mathrm{a}, \mathrm{b}}$ & $0.081^{\mathrm{a}}$ \\
CIN $^{\mathrm{b}}$ & 30 & $21(67)$ & $9(33)$ & $5.241^{\mathrm{b}, \mathrm{d}}$ & 0.022 \\
Adenocarcinoma $^{\mathrm{c}}$ & 16 & $13(81)$ & $3(19)$ & $6.828^{\mathrm{c}, \mathrm{d}}$ & 0.009 \\
SCC $^{\mathrm{d}}$ & 73 & $33(45)$ & $40(55)$ & $10.577^{\mathrm{a}, \mathrm{d}}$ & 0.001 \\
\hline
\end{tabular}

${ }^{\text {a}}$ Fisher's value.

Table III. Correlation between expression of stromal Cav-1 and clinicopathological parameters of cervical squmous cell carcinomas.

\begin{tabular}{lrrrrr}
\hline & \multicolumn{5}{c}{ Stromal Cav-1 } \\
\cline { 3 - 4 } Group & Cases & $-(\%)$ & $+(\%)$ & $\chi^{2}$ & P-value \\
\hline Grade & & & 0.262 & 0.609 \\
I+II & 21 & $15(71)$ & $6(29)$ & & \\
III & 37 & $24(65)$ & $13(35)$ & & \\
Tumour & & & & 0.185 & 1.000 \\
T1 & 47 & $31(66)$ & $16(34)$ & & \\
$>$ T1 & 11 & $8(73)$ & $3(27)$ & & \\
TNM stage & & & & 1.618 & 0.203 \\
I+II & 40 & $29(72)$ & $11(28)$ & & \\
III+IV & 18 & $10(56)$ & $8(44)$ & & \\
Lymph & & & & 2.233 & 0.135 \\
node status & & & & \\
$\mathrm{N}_{0}$ & 41 & $30(73)$ & $11(27)$ & & \\
$\mathrm{N}_{1-3}$ & 17 & $9(53)$ & $8(47)$ & & \\
\hline
\end{tabular}

respectively. Table II showed Cav-1 protein expression in the different cervical lesions. Significant difference of Cav-1 expression was observed between SCC and the other three groups $(\mathrm{P}<0.05)$. In a pairwise comparison between the other three groups, no significant difference of Cav-1 expression was observed.

Only 58 cases of 73 cervical SCC had sufficient tissue for analysis of both epithelial and stromal Cav-1 immunostaining. Representative examples of tumours with $\mathrm{Cav}-1$ positive and negative stromal tissue are shown in Fig. 2B and C. Thirty-nine specimens (67\%) showed an absence of stromal Cav-1 levels. According to the criteria of the current study, the positive rates of stromal Cav-1 in the cervical SCC was 33\% (19/58). To further explore the relationship between Cav-1 levels in the tumour microenvironment and cervical SCC progression, we detected Cav-1 immunoreactivity in 58 primary cervical SCC and specifically analyzed the amount of Cav-1 protein either in tumour cells or stromal cells. In 39 stromal Cav-1 negative cases, 22 cases showed positive expression of Cav-1 protein in tumour cells. In 19 stromal Cav-1 positive cases, 13 cases showed negative expression of Cav-1 protein in tumour cells. Seventeen positive cases and 6 negative cases of cervical SCC demonstrated co-expression of Cav-1 protein in tumour and stromal cells. While both relationships showed a negative correlation tendency, it was not statistically significant $(\mathrm{P}=0.076)$.

Clinical significance of Cav-1 expression in tumour and stromal cells. Table I shows the correlation between Cav-1 expression in tumour cells and different clinicopathological parameters in univariate analyses. In the TNM stage I+II, positive rates of Cav-1 protein in tumour cells was $62 \%$ $(32 / 52)$, higher than $38 \%(8 / 21)$ of III+IV, but the difference was not significant. No significant association was found between staining intensity of Cav-1 in tumour cells and the other clinicopathological parameters of SCC.

Correlation between stromal Cav-1 expression and different clinicopathological parameters of cervical SCC as shown in Table III. Positive rates of stromal Cav-1 expression in high TNM stages and with lymph node metastasis was higher than those in low TNM stages and without lymph node metastasis, but no significant differences was observed. There were no significance between stromal Cav-1 expression and tumour cell differentiation degree and invasive range.

Correlation between Cav-1 expression in tumour cells and cell proliferation, HR-HPV infection. Quantum dot double immunofluorescent labeling method was used to detect co-expression of Cav-1 and PCNA proteins in 73 cases of cervical SCC. Positive signals of PCNA were bright red, located in the cell nucleus, while Cav-1 were green and located in the cytoplasm (Fig. 2E and F). Negative co-expression of Cav-1 and PCNA in tumour cells was seen in 13 cases, and 39 cases were positive for co-expression of Cav-1 and PCNA in tumour cells, both correlations were significantly positive $(\mathrm{r}=0.466, \mathrm{P}=0.000)$.

Positive signal pattern of HPV 16/18 showed punctate, diffuse or mixed nuclear staining (Fig. 3). ISH reactions for HPV 16/18 were positive in $77 \%$ (56/73) cases of cervical SCC. In 17 HPV 16/18 DNA negative cases, 12 cases showed negative expression of Cav-1 protein in tumour cells. In 56 HPV 16/18 DNA positive cases, 35 cases showed positive expression of Cav-1 protein in tumour cells, both demonstrated a significantly positive correlation $(r=0.281, \mathrm{P}=0.016)$. 


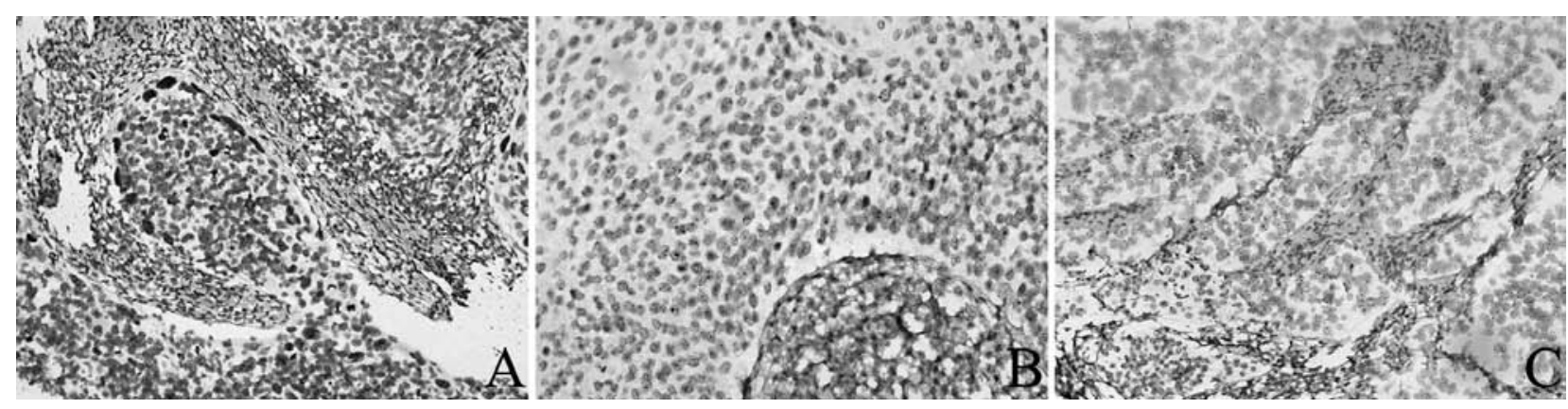

Figure 3. HPV 16/18 infection detected by in situ hybridization in the cervical squamous cell carcinoma. Positive signal pattern of HPV 16/18 showed (A) diffuse, (B) mixed and (C) punctate nuclear staining (DAB staining, original magnification, $\mathrm{x} 400$ ).

\section{Discussion}

It has become increasingly clear that Cav-1 is a multifunctional scaffolding protein, can regulate multiple cancer-associated processes including cellular transformation, tumour growth, cell migration and metastasis, cell death and survival, multidrug resistance and angiogenesis by binding cell surface signal molecules (19). However, Cav-1 has been reported to impact both positively and negatively on various aspects of tumour progression. Some studies have reported that Cav-1 function as a tumour suppressor, but others have identified Cav-1 as a poor prognostic factor in various human cancers. It is very interesting that difference of caveolin-1 expression pattern is detected in the different histology subtype such as SCC and AC of lung (20). Even in the same histology type such as SCC, Cav-1 also has a different expression pattern. In vivo study of tongue (7), esophagus $(8,18)$, bladder (21), lung (22) and nasopharynx (23) SCC demonstrated overexpression of Cav-1 protein in the tumour cells, and is closely correlated with tumor progression and poor prognosis $(18,23)$. Nevertheless, in the primary head and neck squamous cell carcinoma (HNSCC), Cav-1 may play an inhibitory role in tumourigenesis and lung metastasis (24). On the contrary, other studies show that Cav-1 is able to mediate tumour cell migration and invasion and its regulation by miR-133a in HNSCC, and thus as an oncogene in HNSCC (25). In the development of cervical cancer, inactivation of the Cav-1 gene by mutation or methylation of the promoter may play a very limited role (26), or relate with an unknown mechanism. Hence there is a need to further investigate the actual role of the Cav-1 gene in the development and progression of cervical cancer.

In our study, expression of Cav-1 protein was detected by QD-IHC in the different cervical lesions. Positive staining of Cav-1 protein was observed in the cervical SCC, adenocarcinoma, CIN and stroma such as capillary endothelial cells, fibroblasts and smooth muscle cells. Focal dot-like Cav-1 staining was found in the basal cells of normal cervical squamous epithelium, but completely negative in the cervical glandular epithelium. The results demonstrated that the expression pattern of Cav-1 is dependant on the histological subtype. We found that the positive rates of Cav-1 in the normal cervical squamous epithelium, CIN, cervical SCC was $0(0 / 10), 33 \%(9 / 30)$ and $55 \%(40 / 73)$, respectively, suggesting a gradient increase of Cav-1 levels follow with malignant progress of cervical squamous epithelium. The difference of Cav-1 protein was significant in the cervical SCC group compared with the other two groups, implying that Cav-1 functions as an oncogene in the development of cervical SCC. We previously reported that Cav-1 might be an oncogene in the development and progress of human tongue SCC (7). But our study also found that Cav-1 protein was positive in $19 \%(3 / 16)$ cervical AC tissues, significantly lower than 55\% (40/73) of cervical SCC, suggesting that Cav-1 has different biological functions in the cervical adenocarcinoma, more studies are warranted. Our study further analysed the correlation between Cav-1 expression in tumour cells and clinicopathological parameters, and found that positive rates of Cav-1 protein in the T2+T3 stage was $73 \%$ (8/11), higher than $52 \%(32 / 62)$ of $\mathrm{T} 1$ stage, although no significant difference was observed, these results manifested that Cav-1 may relate with the infiltrating extent of cervical SCC. However, no significant correlation was elucidated between levels of Cav-1 and the other clinicopathalogical parameters. A significant correlation can be observed between Cav-1 immunostaining and $\mathrm{T}$ factor, lymphatic invasion, vein invasion and differentiation of esophageal SCC (18). There is also positive correlation between the expression of Cav-1 protein and tumour grade and squamous features of urothelial carcinoma of the urinary bladder (27). Eventually, positive staining for Cav-1 could be a potentially useful prognostic marker of esophageal SCC (18) and pulmonary SCC (28). Our results further identify that Cav-1 has a different expression pattern in the same SCC subtype of different organs.

Recently, some studies reported that high levels of Cav-1 in the stromal tissue surrounding the tumour, rather than within tumour cells, are associated strongly with reduced metastasis and improved survival. However, a loss of stromal Cav-1 in cancer-associated fibroblasts can be regarded as a powerful single independent predictor of breast cancer patient tumour recurrence, metastasis, tamoxifen-resistance, and poor clinical outcome $(16,29,30)$. Stromal levels of Cav-1 are also significantly decreased in the primary prostate cancer, and correlated with a high Gleason score, indicative of a worse prognosis and poor clinical outcome (31). An absence of stromal Cav-1 may be a potential therapeutic target and valuable prognostic indicator of breast and prostate cancer progression. Nevertheless, the interaction of Cav-1 between tumour and stromal cells remains unclear. In the present 
study, we examined Cav-1 expression in tumour and stromal cells by QD-IHC analysis in 58 primary cervical SCC tissues. Thirty-nine of 58 cervical SCC specimens (67\%) showed an absence of stromal Cav-1. Expression of Cav-1 in the tumour and stromal cells had a negative correlation tendency, but no significance was detected, suggesting that Cav-1 may have a different biological function in the tumour and stroma. Absent rates of stromal Cav-1 expression in high TNM stages and with lymph node metastasis was lower than those in low TNM stages and without lymph node metastasis, but no significant differences was observed. Moreover, stromal Cav-1 expression was not related with tumour cell differentiation degree and invasive range. From the above results, we could not conclude that Cav-1 functions as a tumour suppressor or oncogene in the stromal microenvironment, further studies are needed to determine the roles of stromal Cav-1. Possibly the stromal Cav-1 function in the SCC is different from adenocarcinoma such as breast and prostate cancer.

Quantum dots, which are also called fluorescent semiconductor nanocrystals, have extraordinary fluorescent properties including high brightness, high stability against photobleaching and tunable wavelengths. Different QDs in the same experiment could be excited by monochromatic light, do not need to convert filters and make the multicolor imaging possible (32). In this study, QDs double immunofluorescent labeling method was used to detect co-expression of Cav-1 and PCNA proteins in the tumour cells of cervical SCC, and both showed a significant positive correlation which indicated that Cav-1 has the ability to promote cervical SCC progression by enhancing cell proliferation capabilities.

HR-HPV infection is the most important event in the malignant transformation of cervical epithelium. Different signal patterns of HR-HPV are detected by using ISH, which has a diffuse, punctate and mixed signal, especially punctate signal is related with malignant transformation of cervical epithelium (33). We found that 77\% (56/73) of cervical SCC tissues was positive for HPV $16 / 18$ by ISH, and reported that a significant positive correlation was observed between expression of Cav-1 in tumour cells and HPV 16/18 infection, suggesting that Cav-1 can promote the progress of cervical SCC, and may have an association with HR-HPV infection.

In summary, we have identified Cav-1 expression in tumour cells, rather than in the stromal tissue surrounding the tumour, possibly contributing to cervical cancer progression by enhancing cell proliferation. We also demonstrate that Cav-1 in the tumour and stroma has a different biological function in cervical SCC. The data provide additional mechanisms of Cav-1 promoting cervical SCC progression, that may associate with HR-HPV infection.

\section{Acknowledgements}

This study was partly supported by grants from the National Natural Science Foundation of China (no. 30900652).

\section{References}

1. Wallin KL, Wiklund F, Angstrom T, Bergman F, Stendahl U, Wadell G, Hallmans G and Dillner J: Type-specific persistence of human papillomavirus DNA before the development of invasive cervical cancer. N Engl J Med 341: 1633-1638, 1999.
2. Munoz N, Bosch X, de Sanjose S, Herrero R, Castellsagué X, Shah KV, Snijders PJ and Meijer CJ: Epidemiological classification of human papillomavirus types associated with cerivcal cancer. N Engl J Med 348: 518-527, 2003.

3. Williams TM, Hassan GS, Li J, Cohen AW, Medina F, Frank PG, Pestell RG, Di Vizio D, Loda M and Lisanti MP: Caveolin-1 promotes tumor progression in an autochthonous mouse model of prostate cancer; genetic ablation of Cav-1 delays advanced prostate tumor development in tramp mice. J Biol Chem 280: 25134-25145, 2005.

4. Suzuoki M, Miyamoto M, Kato K, Hiraoka K, Oshikiri T, Nakakubo Y, Fukunaga A, Shichinohe T, Shinohara T, Itoh T, et al: Impact of caveolin-1 expression on prognosis of pancreatic ductal adenocarcinoma. Br J Cancer 87: 1140-1144, 2002.

5. Van den Eynden GG, van Laere SJ, van der Auwera I, Merajver SD, Van Marck EA, van Dam P, Vermeulen PB, Dirix LY and van Golen KL: Overexpression of caveolin-1 and -2 in cell lines and in human samples of inflammatory breast cancer. Breast Cancer Res Treat 95: 219-228, 2006.

6. Fine SW, Lisanti MP, Galbiati F and Li M: Elevated expression of caveolin-1 in adenocarcinoma of the colon. Am J Clin Pathol 115: 719-724, 2001.

7. Xue J, Chen H, Diao L, Chen X and Xia D: Expression of caveolin-1 in tongue squamous cell carcinoma by quantum dots. Eur J Histochem 54: 99-103, 2010.

8. Kato K, Hida Y, Miyamoto M, Shinohara T, Itoh T, Okushiba S, Kondo S and Katoh H: Overexpression of caveolin-1 in esophageal squamous cell carcinoma correlates with lymph node metastasis and pathologic stage. Cancer 94: 929-933, 2002.

9. Wikman H, Seppanen JK, Sarhadi VK, Kettunen E, Salmenkivi K, Kuosma E, Vainio-Siukola K, Nagy B, Karjalainen A, Sioris T, et al: Caveolins as tumour markers in lung cancer detected by combined use of cDNA and tissue microarrays. J Pathol 203: 584-593, 2004.

10. Bender FC, Reymond MA, Bron C and Quest AF: Caveolin-1 levels are down-regulated in human colon tumors, and ectopic expression of caveolin-1 in colon carcinoma cell lines reduces cell tumorigenicity. Cancer Res 60: 5870-5878, 2000.

11. Davidson B, Nesland JM, Goldberg I, Kopolovic J, Gotlieb WH, Bryne M, Ben-Baruch G, Berner A and Reich R: Caveolin-1 expression in advanced-stage ovarian carcinoma: a clinicopathologic study. Gynecol Oncol 81: 166-171, 2001.

12. Park SS, Kim JE, Kim YA, Kim YC and Kim SW: Caveolin-1 is down-regulated and inversely correlated with HER 2 and EGFR expression status in invasive ductal carcinoma of the breast. Histopathology 47: 625-630, 2005.

13. Sloan EK, Stanley KL and Anderson RL: Caveolin-1 inhibits breast cancer growth and metastasis. Oncogene 23: 7893-7897, 2004.

14. Burgermeister E, Xing X, Röcken C, Juhasz M, Chen J, Hiber M, Mair K, Shatz M, Liscovitch M, Schmid RM and Ebert MP: Differential expression and function of caveolin-1 in human gastric cancer progression. Cancer Res 67: 8519-8526, 2007.

15. Aldred MA, Ginn-Pease ME, Morrison CD, Popkie AP, Gimm O, Hoang-Vu C, Krause U, Dralle H, Jhiang SM, Plass C and Eng C: Caveolin-1 and caveolin-2,together with three bone morphogenetic protein-related genes, may encode novel tumor suppressors down-regulated in sporadic follicular thyroid carcinogenesis. Cancer Res 63: 2864-2871, 2003.

16. Witkiewicz AK, Dasgupta A, Sotgia F, Mercier I, Pestell RG, Sabel M, Kleer CG, Brody JR and Lisanti MP: An absence of stromal caveolin-1 expression predicts early tumor recurrence and poor clinical outcome in human breast cancers. Am J Pathol 174: 2023-2034, 2009.

17. Chen H, Xue J, Zhang Y, Gao J and Yu B: Comparison of quantum dots immunofluorescence histochemistry and conventional immunohistochemistry for the detection of caveolin- 1 and PCNA in the lung cancer tissue microarray. J Mol Histol 40: 261-268, 2009.

18. Ando T, Ishiguro H, Kimura M, Mitsui A, Mori Y, Sugito N, Tomoda K, Mori R, Harada K, Katada T, Ogawa R, Fujii Y and Kuwabara Y: The overexpression of caveolin-1 and caveolin-2 correlates with a poor prognosis and tumor progression in esophageal squamous cell carcinoma. Oncol Rep 8: 601-609, 2007.

19. Goetz JG, Lajoie P, Wiseman SM and Nabi IR: Caveolin-1 in tumor progression; the good, the bad and the ugly. Cancer Metastasis Rev 27: 715-735, 2008 
20. Cassoni P, Daniele L, Maldi E, Righi L, Tavaglione V, Novello S, Volante M, Scagliotti GV and Papotti M: Caveolin-1 expression in lung carcinoma varies according to tumour histotype and is acquired de novo in brain metastases. Histopathology 55: 20-27, 2009.

21. Kunze E, Von Bonin F, Werner C, Wendt M and Schlott T: Transitional cell carcinomas and nonurothelial carcinomas of the urinary bladder differ in the promoter methylation status of the caveolin-1, hDAB2IP and p53 genes, but not in the global methylation of Alu elements. Int J Mol Med 17: 3-13, 2006.

22. Chen HL, Fan LF, Gao J, Ouyang JP and Zhang YX: Differential expression and function of caveolin-1 gene in non-small cell lung carcinoma. Oncol Rep 25: 359-366, 2011.

23. Du ZM, Hu CF, Shao Q, Huang MY, Kou CW, Zhu XF, Zeng YX and Shao JY: Upregulation of caveolin-1 and CD147 expression in nasopharyngeal carcinoma enhanced tumor cell migration and correlated with poor prognosis of the patients. Int J Cancer 125: 1832-1841, 2009.

24. Zhang H, Su L, Müller S, Tighiouart M, Xu Z, Zhang X, Shin HJ, Hunt J, Sun SY, Shin DM and Chen ZG: Restoration of caveolin-1 expression suppresses growth and metastasis of head and neck squamous cell carcinoma. Br J Cancer 99: 1684-1694, 2008.

25. Nohata N, Hanazawa T, Kikkawa N, Mutallip M, Fujimura L, Yoshino H, Kawakami K, Chiyomaru T, Enokida H, Nakagawa M, et al: Caveolin-1 mediates tumor cell migration and invasion and its regulation by miR-133a in head and neck squamous cell carcinoma. Int J Oncol 38: 209-217, 2011.

26. Chan TF, Su TH, Yeh KT, Chang JY, Lin TH, Chen JC, Yuang SS and Chang JG: Mutational, epigenetic and expressional analyses of caveolin-1 gene in cervical cancers. Int J Oncol 23: 599-604 2003.
27. Fong A, Garcia E, Gwynn L, Lisanti MP, Fazzari MJ and Li M: Expression of caveolin-1 and caveolin-2 in urothelial carcinoma of the urinary bladder correlates with tumor grade and squamous differentiation. Am J Clin Pathol 120: 93-100, 2003.

28. Yoo SH, Park YS, Kim HR, Sung SW, Kim JH, Shim YS, Lee SD, Choi YL, Kim MK and Chung DH: Expression of caveolin-1 is associated with poor prognosis of patients with squamous cell carcinoma of the lung. Lung Cancer 42: 195-202, 2003.

29. Sloan EK, Ciocca DR, Pouliot N, Natoli A, Restall C, Henderson MA, Fanelli MA, Cuello-Carrión FD, Gago FE and Anderson RL: Stromal cell expression of caveolin-1 predicts outcome in breast cancer. Am J Pathol 174: 2035-2043, 2009.

30. Qian N, Ueno T, Kawaguchi-Sakita N, Kawashima M, Yoshida N, Mikami Y, Wakasa T, Shintaku M, Tsuyuki S, Inamoto T and Toi M: Prognostic significance of tumor/stromal caveolin-1 expression in breast cancer patients. Cancer Sci 102: 1590-1596, 2011.

31. Di Vizio D, Morello M, Sotgia F, Pestell RG, Freeman MR and Lisanti MP: An absence of stromal caveolin-1 is associated with advanced prostate cancer, metastatic disease and epithelial Akt activation. Cell Cycle 8: 2420-2424, 2009.

32. $\mathrm{Li} \mathrm{ZH}$, Peng J and Chen HL: Bioconjugated quantum dots as fluorescent probes for biomedical imaging. J Nanosci Nanotechno 11: 7521-7536, 2011.

33. Omori M, Hashi A, Nakazawa K, Yuminamochi T, Yamane T, Hirata S, Katoh R and Hoshi K: Estimation of prognoses for cervical intraepithelial neoplasia 2 by p16INK4a immunoexpression and high-risk HPV in situ hybridization signal types. Am J Clin Pathol 128: 208-217, 2007. 